Check for updates

Cite this: RSC Adv., 2019, 9, 11160

Received 28th January 2019

Accepted 1st April 2019

DOI: $10.1039 / c 9 r a 00742 c$

rsc.li/rsc-advances

\section{Novel synthesis of a clay supported amorphous aluminum nanocomposite and its application in removal of hexavalent chromium from aqueous solutions $\uparrow$}

\begin{abstract}
Nitin Khandelwal, (D a Nisha Singh, ${ }^{a}$ Ekta Tiwari ${ }^{a}$ and Gopala Krishna Darbha (D) *ab
A bentonite supported amorphous aluminum (B-Al) nanocomposite was synthesized by the $\mathrm{NaBH}_{4}$ reduction method in an ethanol-water interfacial solution and characterized with SEM, TEM, XRD, FT-IR and XRF. Surface morphology and line scans obtained from TEM imaging suggest the successful synthesis of the nanocomposite while XRF data shows a drastic change in Al concentration in the synthesized nanocomposite with respect to raw bentonite. This synthesized nanocomposite was further utilized for the removal of hexavalent chromium $(\mathrm{Cr}(\mathrm{vI}))$ from aqueous solutions. The very high removal efficiency of the composite for $\mathrm{Cr}(\mathrm{VI})$ (i.e. $49.5 \mathrm{mg} \mathrm{g}^{-1}$ ) was revealed by the Langmuir sorption isotherm. More than $90 \%$ removal of $\mathrm{Cr}(\mathrm{vI})$ in just 5 minutes of interaction suggests very fast removal kinetics. Inner sphere complexation and coprecipitation of $\mathrm{Cr}(\mathrm{vI})$ can be concluded as major removal mechanisms. No influence of ionic strength suggests inner sphere complexation dominated in $\mathrm{Cr}(\mathrm{vI})$ uptake. $\mathrm{pH}$ of the solution didn't influence the sorption much but comparatively the removal was higher under alkaline conditions (99.4\%) than under acidic conditions (93.7\%). The presence of humic acid and bicarbonate ions reduced the sorption significantly. The final product, $\mathrm{Cr}-\mathrm{Al}(\mathrm{OH})_{3}$ results in precipitation by forming alum which indicates that clay supported amorphous aluminum nanocomposites can be considered as potential sorbents for toxic metal ions in the environment.
\end{abstract}

\section{Introduction}

Toxicity arises in living organisms if heavy metals are present above their permissible concentrations and can damage the whole ecosystem due to their persistency and non-degradability. ${ }^{1-3}$ Increased concentrations of these metal ions in water bodies are mainly attributed to anthropogenic sources. ${ }^{4}$

Out of several toxic metal ions, chromium is one of the most extensively used heavy metals in various industrial activities like in dyes and pigments, electroplating, wood preservation, corrosion inhibition, textiles, copying machine toner, fertilizer manufacture, etc. ${ }^{5,6}$ The maximum permissible limit for chromium has been set at $0.1 \mathrm{mg} \mathrm{L}^{-1}$ by the United States Environmental Protection Agency (USEPA) while the World Health Organization (WHO) and the Bureau of Indian Standards (BIS) set the maximum permissible limit of chromium in drinking

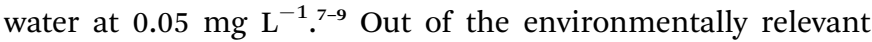

${ }^{a}$ Environmental Nanoscience Laboratory, Indian Institute of Science Education and Research Kolkata, Mohanpur, Kolkata, West Bengal, India, 741246. E-mail: gkdarbha@gmail.com; gkdarbha80@yahoo.com; Tel: +919849626082

${ }^{b}$ Centre for Climate Change and Environmental Studies, Indian Institute of Science Education and Research Kolkata, Mohanpur, West Bengal, India, 741246

$\dagger$ Electronic supplementary information (ESI) available. See DOI: $10.1039 / \mathrm{c} 9 \mathrm{ra} 00742 \mathrm{c}$ forms of $\mathrm{Cr}, \mathrm{Cr}(\mathrm{III})$ is an essential micronutrient, playing a role in glucose metabolism; in contrast, $\mathrm{Cr}(\mathrm{vI})$ is considered as a carcinogen (through inhalation) and is associated with both acute and chronic health effects (by both inhalation and ingestion). ${ }^{10}$

Various removal mechanisms have been reported for chromium remediation like chemical precipitation, oxidation/ reduction, membrane filtration, ion-exchange and adsorption, among all sorption is a simple, effective, and economical method for contaminant remediation. ${ }^{\mathbf{1 1 - 1 3}}$ Many adsorbents have been synthesized so far and used to remove chromium. ${ }^{13-22}$ For example, recently, nano zero valent iron (nZVI) has been explored for the removal of chromium ${ }^{23-26}$ but intense oxidation, iron release and immediate aggregation are the limitations of utilizing nZVI. ${ }^{27}$ Various composites of aluminium $\left(\mathrm{Al}_{2} \mathrm{O}_{3}, \gamma\right.$ $\mathrm{Al}_{2} \mathrm{O}_{3}, \mathrm{Al}(\mathrm{OH})_{3}$ etc.) have been used for the remediation of $\mathrm{Cr}(\mathrm{vI})$ in the environment but only physical sorption resulted in almost complete desorption in just 3 hours. ${ }^{28,29}$

Here, for the first time, we have synthesized amorphous aluminium by $\mathrm{NaBH}_{4}$ reduction method and supported them on bentonite clay to prevent further aggregation of smaller particles and hence to have very high reactivity. Novel clay supported amorphous aluminium was characterized by XRD, TEM-EDS, FT-IR, XRF etc. The synthesized novel nanocomposite 
was further utilized for removal of $\mathrm{Cr}(\mathrm{vI})$ from aqueous solution. Adsorption kinetics and isotherms were studied to elucidate the sorption behaviour of this novel nanocomposite. Various factors which can influence the sorption like $\mathrm{pH}$, temperature, ionic strength have been studied. Effect of complexing agents (bicarbonates and humic acid) on removal of $\mathrm{Cr}(\mathrm{vI})$ have also been explored in detail. After systematic and comparative experiments, reaction precipitate was collected, characterized and analysed by FT-IR and XRD to clarify the possible $\operatorname{Cr}(\mathrm{vI})$ removal mechanisms. Finally this study proposes a new, cost effective and novel nanocomposite for the removal of $\mathrm{Cr}(\mathrm{vI})$ and other heavy metal ions in the environment.

\section{Materials and methods}

\subsection{Materials and chemicals}

Extra pure bentonite clay with the composition (in wt $\%$ ) - 54.9\% $\mathrm{SiO}_{2}, 19.2 \% \mathrm{Al}_{2} \mathrm{O}_{3}, 8.3 \% \mathrm{Fe}_{2} \mathrm{O}_{3}, 1.99 \% \mathrm{MgO}, 0.17 \% \mathrm{CaO}, 1 \%$ $\mathrm{K}_{2} \mathrm{O}$ and $3.79 \% \mathrm{Na}_{2} \mathrm{O}$ was obtained from Loba chemie Pvt. Ltd. and used for experiments without further processing. Following chemicals of analytical purity were purchased from MerckEthanol, $\mathrm{NaBH}_{4}, \mathrm{~K}_{2} \mathrm{Cr}_{2} \mathrm{O}_{7}, \mathrm{NaCl}, \mathrm{KCl}, \mathrm{CaCl}_{2}, \mathrm{MgCl}_{2}, \mathrm{AlCl}_{3}$, $\mathrm{HCl}, \mathrm{NaOH}, \mathrm{NaHCO}_{3}$. Humic acid was obtained from SigmaAldrich. All solutions were prepared with 18.2 M $\Omega$ Milli-Q water.

\subsection{Synthesis of clay supported amorphous aluminium}

Bentonite and aluminum were chosen due to their very high abundance on Earth's crust. While $\mathrm{NaBH}_{4}$ was chosen as reducing agent and also to minimize $\mathrm{Al}$ oxidation during synthesis.

Briefly bentonite clay and aluminum salt $\left(\mathrm{AlCl}_{3}\right)$ were taken with a clay/Al mass ratio of $1: 1 \mathrm{in} 50 \mathrm{ml}$ interfacial solution (ethanol + water $=4: 1$ ) and sonicated for 30 minutes then under continuous magnetic stirring, $100 \mathrm{ml}$ of $0.93 \mathrm{M} \mathrm{NaBH}_{4}$ was then added dropwise with a constant flow rate of 4.5

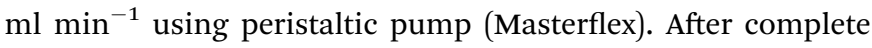
addition of $\mathrm{NaBH}_{4}$, mixtures were vigorously stirred for another 20 minutes and cream coloured product was filtered and washed thoroughly 5 times with absolute ethanol. Obtained material was vacuum dried in an oven, powdered and stored for further characterization and sorption experiments. $\mathrm{Al}^{3+}$ has very high ionic potential and hence can easily be exchanged with other ions present in interlayer spaces of clay, during initial sonication and magnetic stirring. Oxidation will be minimum in these spaces due to hindrance. ${ }^{30,31}$

\subsection{Characterizations and measurements}

Field emission scanning electron microscope (FESEM) images were obtained using Carl Zeiss SUPRA 55VP FESEM. Transmission electron microscopy (TEM) images were obtained by JEOL, JEM 2100 HR model. Energy dispersive analysis of X-ray (EDAX) studies were performed with the Oxford Instruments X-Max with INCA software coupled to both FESEM and TEM. Zeta potentials and $\mathrm{pH}_{\mathrm{PZC}}$ in aqueous suspension solution were measured with a Malvern Zetasizer ZS-90 dynamic light scattering (DLS) instrument. X-ray diffraction (XRD) measurements were performed with a Rigaku (mini flex II, Japan) powder X-ray diffractometer having a high-power $\mathrm{Cu}-\mathrm{K} \alpha$ radioactive source (wavelength $=0.154 \mathrm{~nm}$ ) at $40 \mathrm{kV} / 70 \mathrm{~mA}$. All samples were scanned from $5^{\circ}$ to $90^{\circ} 2 \theta$ range at a scanning rate of $3^{\circ} 2 \theta$ per minute. The Fourier transform infrared (FTIR) spectroscopy studies were carried out with a PerkinElmer spectrum RX1 with $\mathrm{KBr}$ pellets. The residual $\mathrm{Cr}(\mathrm{vr})$ in solution was analyzed using the 1,5-diphenylcarbazide method with a UV-Visible spectrophotometer (Evolution 201, Thermo-Fisher Scientific) at wavelength of $540 \mathrm{~nm}$. Aluminum concentration in raw bentonite and synthesized nanocomposite was determined by fusion beads X-ray fluorescence spectroscopy (S8 TIGER 4 kW, Bruker).

\subsection{Batch sorption experiments and control}

Batch experiments were carried out under room temperature. For chromium removal, based on the solid to solution ratio sorption experiment (Fig. S1†), $15 \mathrm{mg}$ of nanocomposite (m) was added in $25 \mathrm{ml}$ (v) of $10 \mathrm{ppm}$ chromium aqueous solution $\left(\mathrm{C}_{0}\right)$ in $50 \mathrm{ml}$ centrifuge tubes at circumneutral $\mathrm{pH}$ condition. Reaction mixtures were placed on a shaker at $200 \mathrm{rpm}$ for $24 \mathrm{~h}$ at $25{ }^{\circ} \mathrm{C}$, then the mixtures were filtered using $0.45 \mu \mathrm{m}$ filter paper (Merck Millipore) and elute were analysed for residual chromium concentrations $\left(C_{\mathrm{e}}\right)$ using $\mathrm{UV}$-Vis spectrophotometer (Calibration curve attached Fig. S2 $\dagger$ ). To assure QA/QC of obtained data, controlled experiments were carried out in parallel by providing similar conditions but without adding nanocomposite and blanks were run without adding chromium in the aqueous solutions. All experiments were carried out in duplicates and relative error was less than $5 \%$, hence error bars are eliminated for better visualization of the data. Removal (\%) and sorption capacity $(q)$ was calculated as

$$
\begin{gathered}
\text { Removal }(\%)=\frac{C_{0}-C_{t}}{C_{0}} \times 100 \% \\
\text { Sorption capacity }(q)=\left(C_{0}-C_{t}\right) \times \frac{V}{m}
\end{gathered}
$$

\section{Results and discussions}

\subsection{Nanocomposite characterization}

The surface morphology of bentonite clay was characterized by both scanning electron microscopy (SEM) and transmission electron microscopy (TEM). TEM imaging, HRTEM and line scanning was also performed for the characterization of synthesized nanocomposite. Clay flakes of less than $2 \mu \mathrm{m}$ are clearly visible in both SEM and TEM images in Fig. 1a and b respectively, while spherical shaped or amorphous $\mathrm{Al}$ nanoparticles on the surface of bentonite can be seen in TEM images of nanocomposite (Fig. 1c and d). Diameter of these spherical shaped, non-crystalline or amorphous $\mathrm{Al}$ nanoparticles on clay surface is roughly around $12-18 \mathrm{~nm}$. Particles are homogeneously dispersed on the surface of clay which also helps in preventing the aggregation of these particles.

XRF data (Table 1) shows a drastic increase in Al content and TEM line scan shows increase in $\mathrm{Al}$ intensity along these 

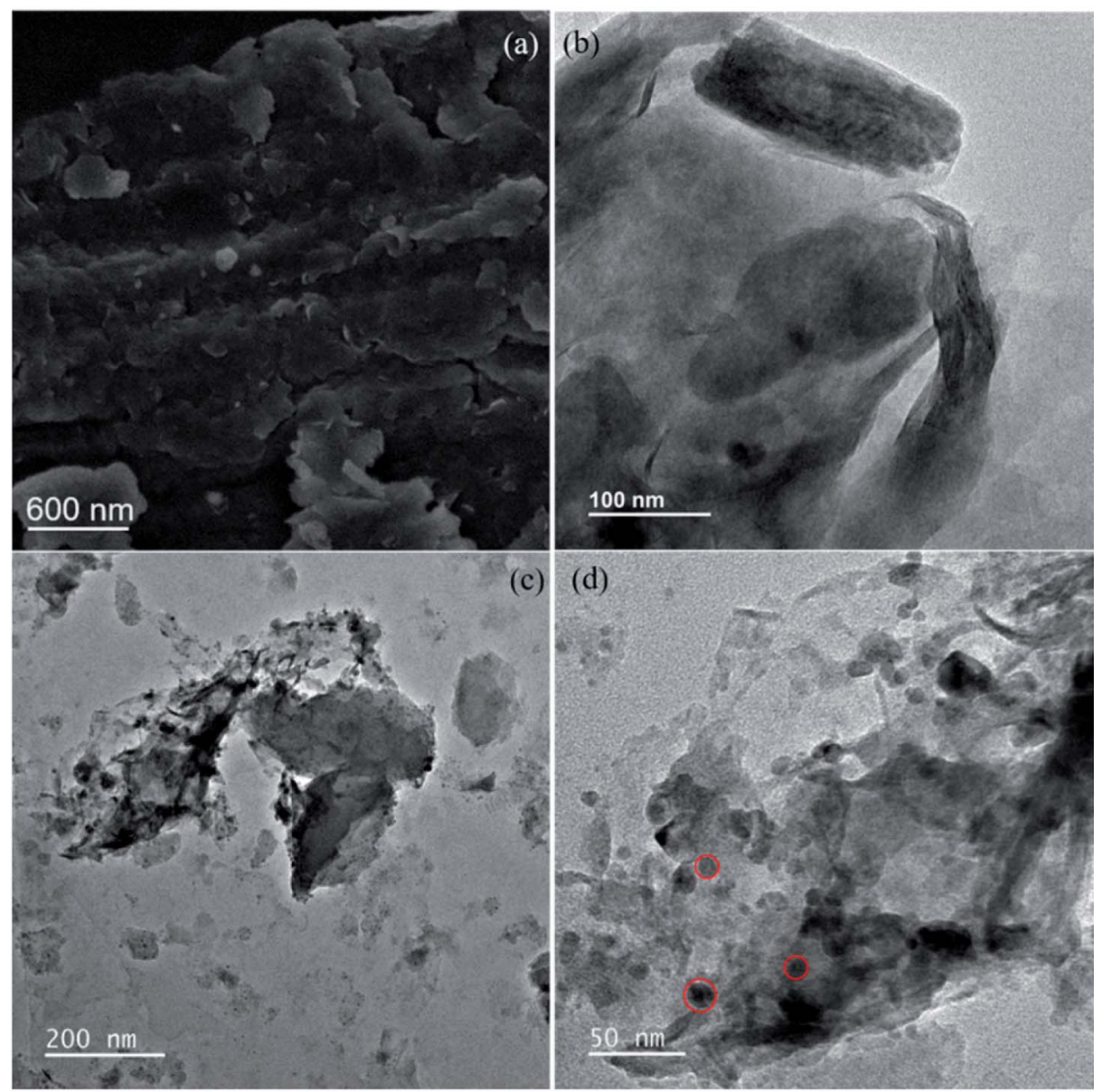

Fig. 1 (a) SEM image of bentonite clay showing $<2 \mu$ m clay flakes, TEM images of (b) bentonite, (c and d) synthesized B-Al composite (red circles highlighting amorphous Al on clay surface).

spheres (Fig. S3†). Results suggests a successful synthesis and supporting of amorphous aluminum.

Fig. 2 shows the FTIR patterns of the prepared nanocomposite. Raw bentonite, B-Al, B-Al-Cr, all composites have broad peaks around $3465 \mathrm{~cm}^{-1}$ which can be attributed to the $\mathrm{OH}$ group stretching while broad bands around $558 \mathrm{~cm}^{-1}$ were related to Al-O stretching vibrations. Si-O bending vibration peak was around $1044 \mathrm{~cm}^{-1}$ as shown in Fig. 2. ${ }^{32,33}$ Antisymmetric stretching vibration of $\mathrm{Si}-\mathrm{O}-\mathrm{Si}$ in the bentonite caused absorption peak near $797 \mathrm{~cm}^{-1}$. The absorption peak near $3626 \mathrm{~cm}^{-1}$ is the vibratory absorption peak of the hydroxyl group. A vibrational absorption peak of $\mathrm{O}-\mathrm{H}$ was at $1632 \mathrm{~cm}^{-1}$, which reflected crystal water in the bentonite lattice. ${ }^{34-38}$ FT-IR data for $\mathrm{B}-\mathrm{Al}-\mathrm{Cr}$ precipitate gives a new absorption peak in $515-550 \mathrm{~cm}^{-1}$ region $\left(525 \mathrm{~cm}^{-1}\right)$ which corresponds to $\mathrm{Cr}_{2} \mathrm{O}_{4}{ }^{2-}$ suggests $\mathrm{Cr}(\mathrm{OH})_{3}$ formation which suggests the reduction of $\mathrm{Cr}(\mathrm{VI})$ to $\mathrm{Cr}(\mathrm{III})$ as a probable removal mechanism..$^{39,40}$
X-ray diffraction patterns of bentonite, B-Al composite and B-AL-Cr precipitate are shown in Fig. 3. The data obtained for all materials shows the peak at $19.7^{\circ}$ which is of sodium bentonite, and the bentonite is $2: 1$ of the mineral structure. The peaks at $21.9^{\circ}$ and $26.6^{\circ}$ represent quartz. The peak at $27.8^{\circ}$ stands for the feldspar. ${ }^{41,42}$ All these peaks are present in B-Al and $\mathrm{B}-\mathrm{Al}-\mathrm{Cr}$, which reveals no change in clay composition after the interaction. As amorphous nature of aluminum can be revealed by TEM images (Fig. 1c and d), obtained XRD peaks in case of B-Al composite can be correlated with cationically exchanged metal ions with $\mathrm{Al}^{3+}$ and reduced by $\mathrm{NaBH}_{4}$ which can be supported with XRD data of B-Al-Cr where the surface has $\mathrm{Al}(\mathrm{OH})_{3}-\mathrm{Cr}$ coprecipitate and hence shows no peaks other than of bentonite.

Presence of new peaks in XRD of B-Al composite corresponds to $\mathrm{Al}_{2} \mathrm{O}_{3}$, suggests presence of an oxide layer on aluminum supported on bentonite clay. Crystallite size

Table 1 XRF data for major elements concentrations in bentonite and B-Al nanocomposite

\begin{tabular}{|c|c|c|c|c|c|c|c|c|c|c|}
\hline Oxides (\%) & $\mathrm{SiO}_{2}$ & $\mathrm{TiO}_{2}$ & $\mathrm{Al}_{2} \mathrm{O}_{3}$ & $\mathrm{Fe}_{2} \mathrm{O}_{3}$ & $\mathrm{MnO}$ & $\mathrm{MgO}$ & $\mathrm{CaO}$ & $\mathrm{Na}_{2} \mathrm{O}$ & $\mathrm{K}_{2} \mathrm{O}$ & $\mathrm{P}_{2} \mathrm{O}_{5}$ \\
\hline Bentonite & 54.91 & 1.828 & 19.24 & 8.3 & 0.06 & 1.99 & 0.17 & 3.79 & 1.01 & 0.089 \\
\hline B-Al & 10.09 & 0.3082 & 39.2 & 1.39 & 0 & 0.36 & 0.01 & 2.78 & 0.18 & 0.0182 \\
\hline
\end{tabular}




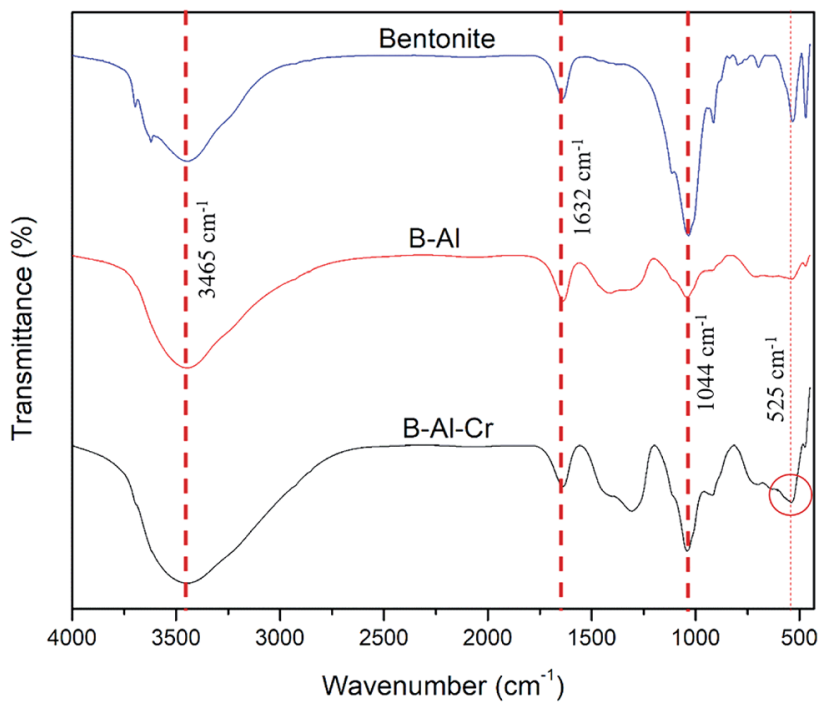

Fig. 2 FT-IR spectra of bentonite, synthesized B-Al nanocomposite and $\mathrm{B}-\mathrm{Al}-\mathrm{Cr}$ reaction precipitate.

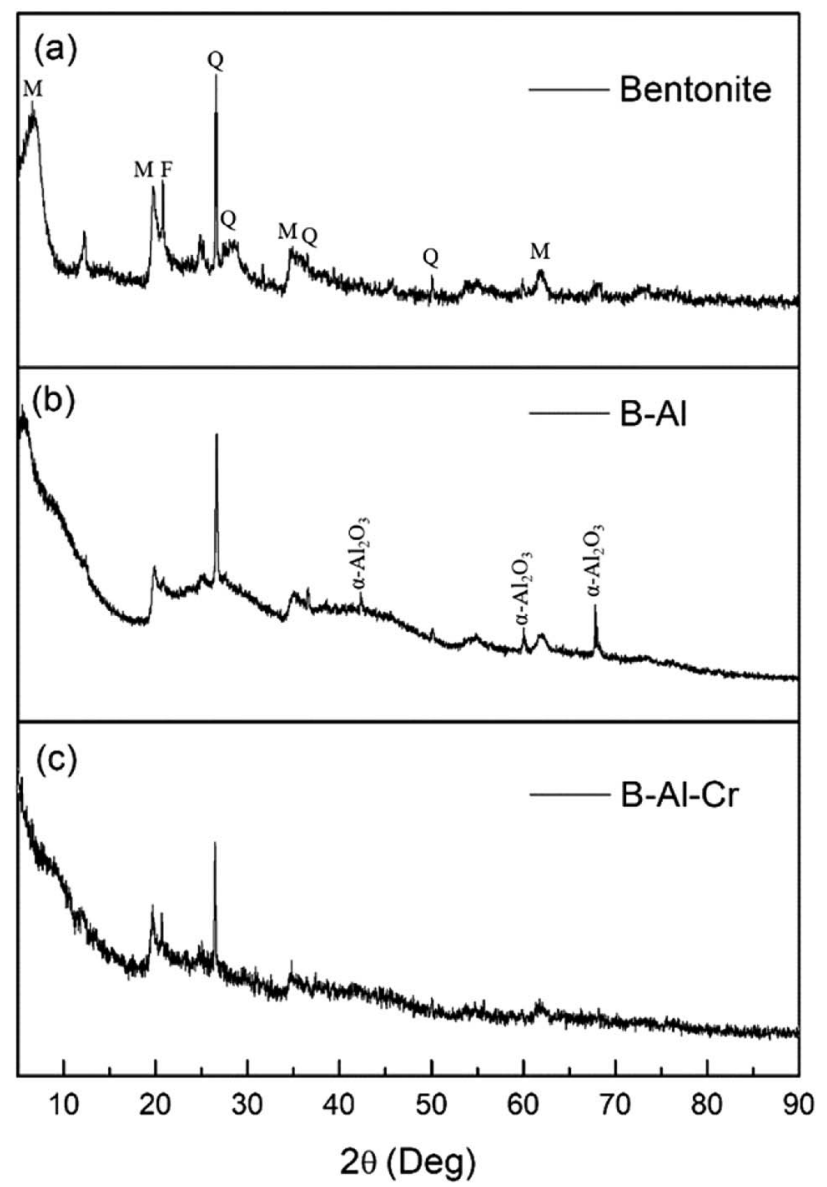

Fig. 3 X-ray diffractogram for (a) bentonite, (b) B-Al nanocomposite and (c) $\mathrm{B}-\mathrm{Al}-\mathrm{Cr}$ precipitate $(\mathrm{M}=$ montmorillonite, $\mathrm{Q}=$ quartz, $\mathrm{F}=$ feldspar).

obtained from XRD data at $60^{\circ} 2$-theta peak was almost equal to $27 \mathrm{~nm}$ while TEM image shows multiple 12-18 nm sized particles.

\section{$3.2 \mathrm{Cr}(\mathrm{vI})$ sorption on nanocomposite}

3.2.1 Sorption kinetics. Experiment was performed to determine the removal kinetics and the data in Fig. 4 shows very fast removal of $\mathrm{Cr}(\mathrm{VI})$ in the solution as more than $90 \%$ of chromium was removed within 5 minutes of reaction. Equilibrium was achieved in 20 minutes of reaction.

To get insights in removal mechanism, pseudo first order, pseudo second order and intraparticle diffusion modelling was performed (Fig. 5a, b and c respectively). Linear form of pseudo first-order reaction kinetics equation, proposed by Lagergren was used to model the $\mathrm{Cr}(\mathrm{vI})$ removal kinetics. Used equation was as follows

$$
\ln \left(q_{\mathrm{e}}-q_{t}\right)=\ln q_{\mathrm{e}}-k_{1} t
$$

where $q_{\mathrm{e}}$ and $q_{t}\left(\mathrm{mg} \mathrm{g}^{-1}\right)$ are the sorption capacities at equilibrium and at time $t$ ( $\mathrm{min})$, respectively. $k_{1}$ is the pseudo-firstorder reaction rate constant $\left(\mathrm{min}^{-1}\right)$ which can be obtained from the slope of the graph between $\ln \left(q_{\mathrm{e}}-q_{t}\right)$ and $t$. Intercept provide the calculated sorption capacity. Data fit was poor as $R^{2}$ $=0.90$ (Fig. 5a) and calculated sorption capacity (Table 2) was very different than experimentally obtained sorption capacity which suggests sorption doesn't follow the first order reaction kinetics. ${ }^{43}$

To analyze the chemisorption kinetics, pseudo second order kinetic equation ${ }^{\mathbf{4 4}}$ was applied

$$
\frac{t}{q_{t}}=\frac{1}{k_{2} q_{\mathrm{e}}^{2}}+\frac{t}{q_{\mathrm{e}}}
$$

where $k_{2}$ is the second order reaction rate constant for pseudo second-order sorption $\left(\mathrm{g} \mathrm{mg}^{-1} \mathrm{~min}^{-1}\right)$. The plot $t / q_{t} v s$. $t$ is linear and can be used to obtained calculated sorption capacity and $k_{2}$. As seen in plot, data show excellent linear fit $\left(R^{2}=0.99\right)$ and calculated $q$ matches with experimental $q$ (Table 2). It shows that sorption follows second order kinetics which suggests chemisorption as a probable removal mechanism. ${ }^{45}$ Data for both kinetic the models are shown in Table 2.

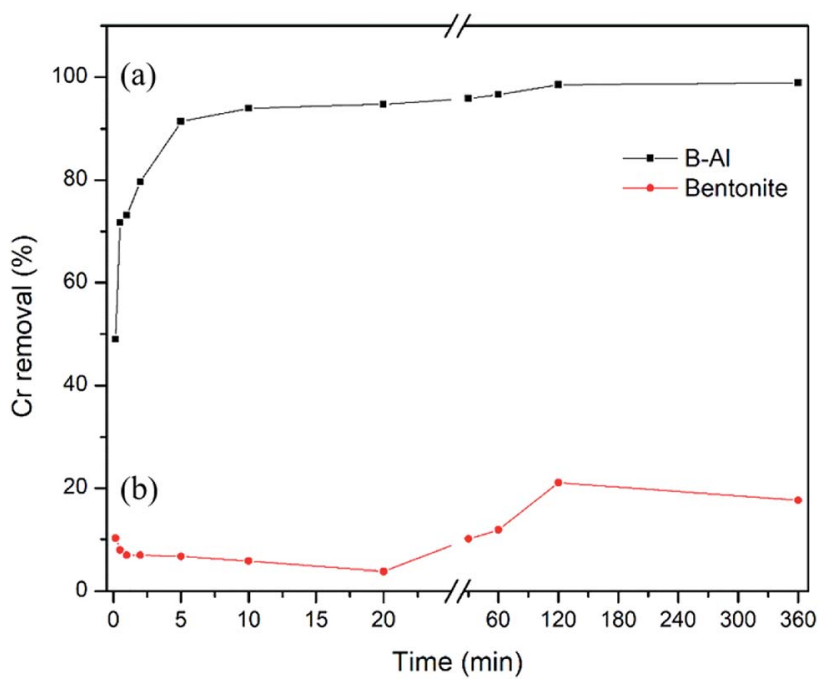

Fig. 4 Effect of time on sorption of $\mathrm{Cr}(\mathrm{VI})$ on (a) raw bentonite and (b) B-Al nanocomposite. 

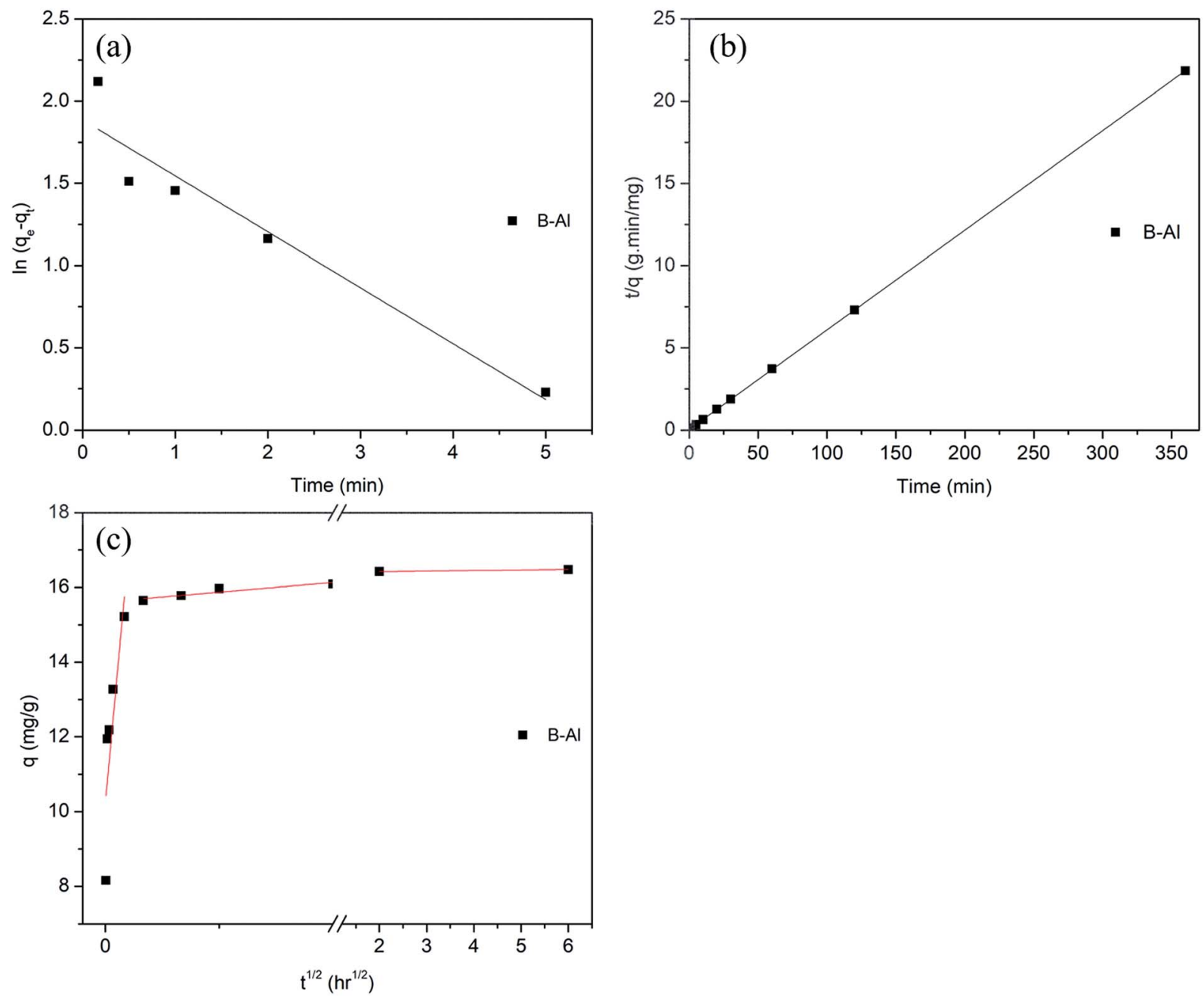

Fig. 5 Various reaction kinetics models (a) pseudo first order, (b) pseudo second order and (c) intra particle diffusion model.

Table 2 Obtained parameters for various reaction kinetics models

\begin{tabular}{llrr}
\hline Model & $K$ & $Q\left(\mathrm{mg} \mathrm{g}^{-1}\right)$ & $R^{2}$ \\
\hline Pseudo first order & $0.35 \mathrm{~min}^{-1}$ & 6.55 & 0.90 \\
Pseudo second order & $0.102 \mathrm{~g} \mathrm{mg}^{-1} \mathrm{~min}^{-1}$ & 16.49 & 0.99 \\
Intraparticle diffusion & $0.52 \mathrm{mg} \mathrm{g}^{-1} \mathrm{~h}^{0.5}$ & & 0.84
\end{tabular}

Intra particle diffusion modelling. Webber's pore-diffusion model (intra particle diffusion) is based on Fick's second law of diffusion and linear form ${ }^{46}$ is as follows

$$
q_{t}=k_{\mathrm{i}} \sqrt{ }
$$

Where $k_{\mathrm{i}}\left(\mathrm{mg} \mathrm{g}^{-1} \mathrm{~h}^{0.5}\right)$ is intra particle diffusion rate constant and $c$ signify resistance in mass transfer due to boundary layer. As shown in Fig. 5c, the plot shows three linear portions which confirm that the external (bulk) mass transfer at the initial stage which is followed by intra particle pore diffusion into macro, meso and micro pores. These three plots can be related to sorption process as follows
(1) film or surface diffusion where the sorbate is transported from the bulk solution to the external surface of sorbent, (2) intraparticle or pore diffusion, where sorbate molecules move into the interior of sorbent particles, and (3) adsorption on the interior sites of the sorbent. It can be seen that adsorption is very rapid and hence it can be assumed that it does not influence the overall removal kinetics. Therefore, surface diffusion or intraparticle diffusion will be the dominant sorption process. ${ }^{47}$

As shown in Fig. 5c, first linear segment which is very steep shows the surface or film diffusion while second gentle slope represents gradual adsorption stage where intraparticle diffusion was rate limiting step and third horizontal line represent 

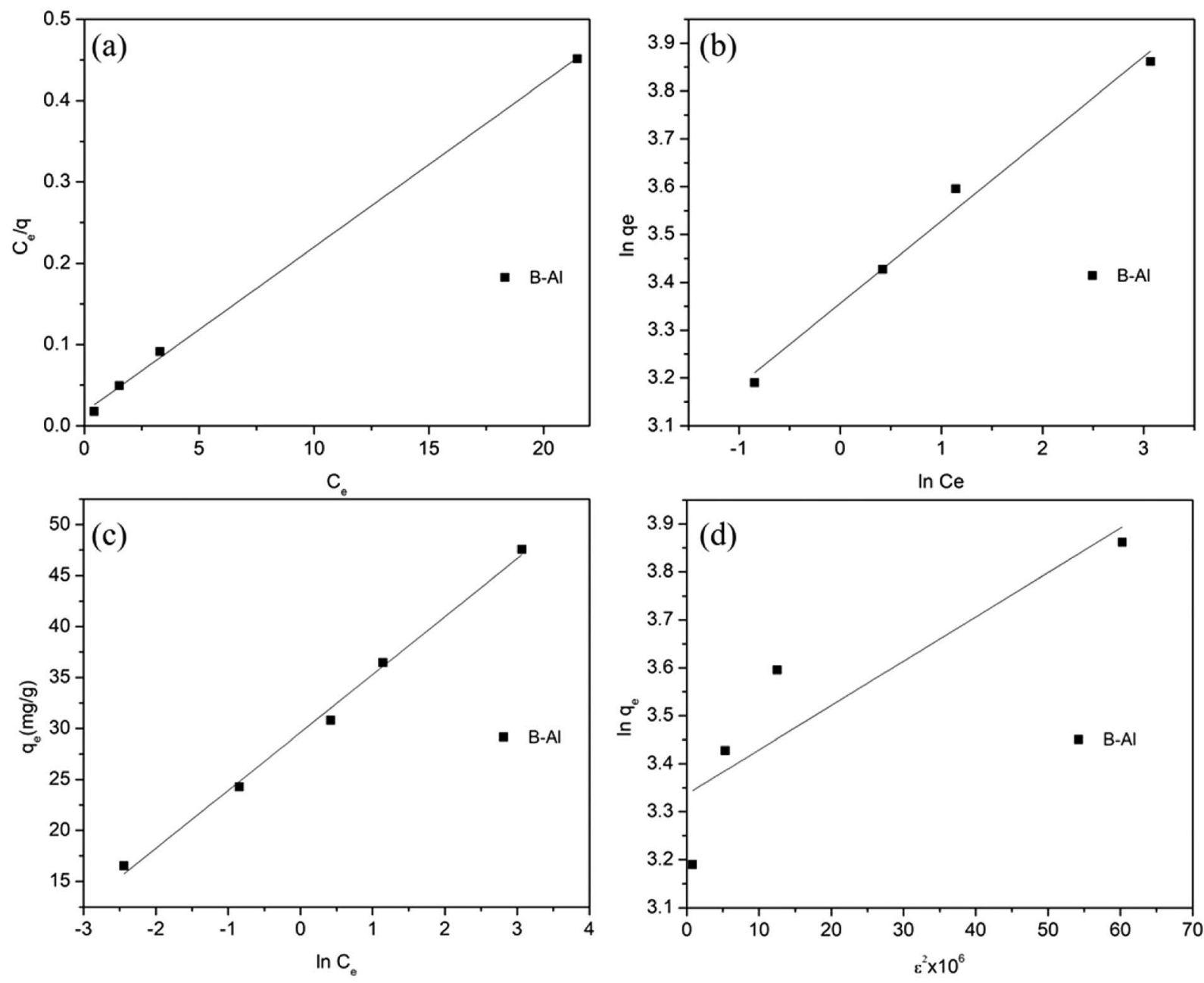

Fig. 6 Various sorption isotherms, (a) Langmuir, (b) Freundlich, (c) Temkin and (d) DKR.

final equilibrium. As the curve is not starting from origin, it can be inferred that intraparticle diffusion was not the only rate limiting step but out of these three steps controlling adsorption, intraparticle diffusion was rate limiting. Data for intercept value and intraparticle diffusion rate constant was also given in Table 2 .

3.2.2 Adsorption isotherms. Data obtained for both Langmuir and Freundlich isotherms (detailed equations in ESI $\dagger$ ) Fig. 6 a and b shows good fit $\left(R^{2}=0.99\right.$ and 0.98 respectively).

Maximum sorption capacity obtained from Langmuir isotherm was $49.5 \mathrm{mg} \mathrm{g}^{-1}$ while the value of ' $n$ ' obtained by Freundlich isotherm (Table 3) was 5.81. $n>1$ suggests strong sorbate-sorbent interaction and chemisorption as removal mechanism. More perfectly following Langmuir isotherm suggests monolayer sorption with uniform sorption affinity of surface.

Temkin isotherm (Fig. 6c, Table 3) assumes chemisorption as the removal process and quite well fit $\left(R^{2}=0.99\right)$ again proves the chemisorption as $\mathrm{Cr}(\mathrm{vI})$ removal mechanism. ${ }^{48}$

Data (Fig. 6d, Table 3) reveals that maximum sorption capacity obtained through DKR isotherm is not matching with $q_{\max }$ obtained through Langmuir isotherm and data fit was also poor $\left(R^{2}\right.$ $=0.70)$ which suggests that sorption is not following DKR isotherm. It reveals that this sorption is not a physical process.
3.2.3 Effect of ionic strength. Ionic strength widely used as a parameter to distinguish metal-adsorbent binding i.e. outer $v s$. inner sphere complexation. Other ions in the solution generally induce site competition. Outer sphere complexes are chiefly electrostatic in nature while inner sphere complexes have covalent characteristics. ${ }^{49,50}$ Compared to inner sphere complexes, outer sphere complexes are more vulnerable site competition. This is because in outer sphere complex, during complex

Table 3 Obtained parameters for various sorption isotherms

\begin{tabular}{ll}
\hline Sorption isotherm model & Parameters \\
\hline Langmuir & $K_{\mathrm{L}}=1.19 \mathrm{~L} \mathrm{mg}^{-1}$ \\
& $q_{\max }=49.5 \mathrm{mg} \mathrm{g}^{-1}$ \\
$R^{2}=0.99$ \\
Freundlich & $K_{\mathrm{F}}=28.68$ \\
& $n=5.81$ \\
& $R^{2}=0.98$ \\
Temkin & $b=0.44 \mathrm{~kJ} \mathrm{~mol}^{-1}$ \\
& $K_{\mathrm{T}}=0.18 \mathrm{~L} \mathrm{~g}^{-1}$ \\
& $R^{2}=0.99$ \\
DKR & $E=134.16 \mathrm{~kJ} \mathrm{~mol}^{-1}$ \\
& $X_{\mathrm{m}}=28.1 \mathrm{mg} \mathrm{g}^{-1}$ \\
$R^{2}=0.70$
\end{tabular}


formation, there is retainment of coordinated water by adsorbed ions, surface functional groups or by both. On the other hand, in an inner sphere surface complex, water is replaced by the surface functional groups with higher coordination affinity, so that immediately adjacent interacting sites can result in formation of electron cloud overlapping to build a strong covalent bond..$^{51,52}$ In this presented study, effect of mono, di and trivalent cation induced ionic strength was evaluated and data shown in Fig. 7 suggests that there is almost no effect of ionic strength on $\mathrm{Cr}(\mathrm{vI})$ removal which strongly suggests inner sphere complexation as a probable removal mechanism.

3.2.4 Effect of pH. Solution $\mathrm{pH}$ is the critical factor which not only influences the form of functional groups on the surface of adsorbents but also dramatically changes the speciation of the metal ions (Fig. S4†). ${ }^{53}$ Both the factors can change the adsorption performance. Effect of $\mathrm{pH}$ was studied over a wide range of $\mathrm{pH}(3-10)$ but no such drastic change in sorption capacity was observed (Fig. 8). A slow decrease in acidic

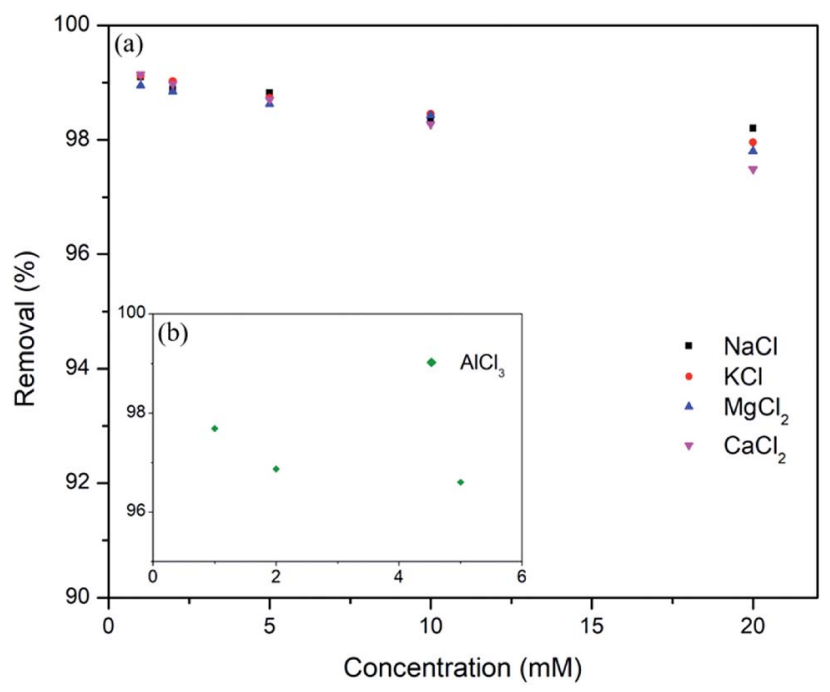

Fig. 7 Effect of ionic strength induced by (a) mono and divalent cations and (b) trivalent cation on removal of $\mathrm{Cr}(\mathrm{VI})$.

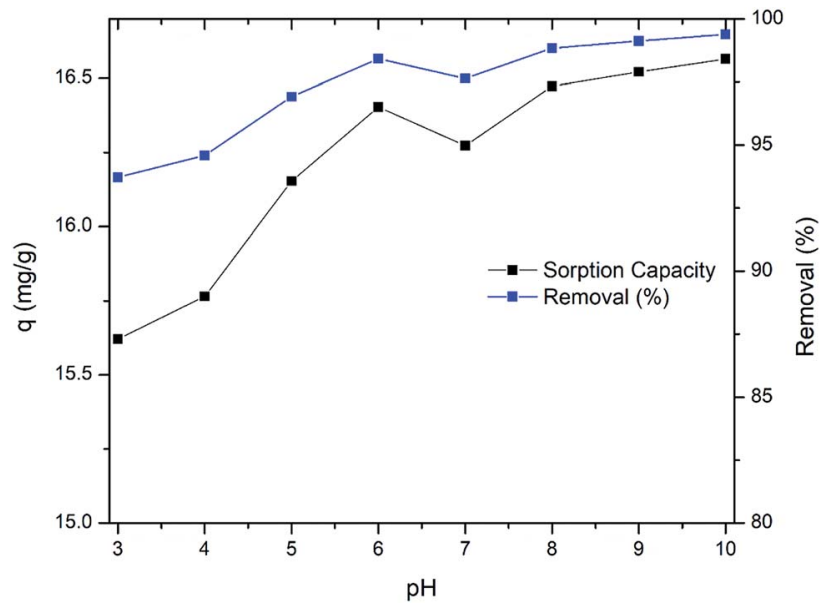

Fig. 8 Effect of initial solution $\mathrm{pH}$ on removal of $\mathrm{Cr}(\mathrm{VI})$ by $\mathrm{B}-\mathrm{Al}$ nanocomposite. environment and increase in alkaline environment in sorption capacity was there which can be related to the metal ion leaching in acidic environment and dominating $\mathrm{Cr}(\mathrm{OH})_{3}$ amorphous chromium specie in alkaline environment.

Generally, clay particles have negative surface over a wide range of $\mathrm{pH}^{54}$ as shown for used bentonite clay in Fig. 9b, a drastic shift was observed in zeta potential (from highly negative to highly positive) after supporting amorphous aluminum on clay surface (Fig. 9a). Point of zero charge $\left(\mathrm{pH}_{\mathrm{PZC}}\right)$ was nearly at $\mathrm{pH}$ 8.68. Which shows that, in environmental conditions ( $\mathrm{pH} 4$ to 8 ) the composite will have +ve charge which will strongly attract the dominant anionic $\operatorname{Cr}(\mathrm{vI})$ species like $\mathrm{HCrO}_{4}{ }^{-}$. Slightly higher sorption capacity at $\mathrm{pH}=6$ can be related to the highest positive zeta potential at this point. ${ }^{55}$

3.2.5 Effect of humic acid. Humic substances are complex organic compounds that are omnipresent in water, soils and sediments as well. ${ }^{56}$ In groundwater and surface water bodies their concentration can range up to $100 \mathrm{mg} \mathrm{L}^{-1}$ with an average of $5 \mathrm{mg} \mathrm{L}{ }^{-1}{ }^{57}$ To see the effect of humic substances, different concentrations of humic acid (HA) were spiked in the $\mathrm{Cr}(\mathrm{VI})$ solution and it was noted (Fig. 10) that increased concentration of HA resulted in drastic decrease in the $\mathrm{Cr}(\mathrm{VI})$ removal which is due to rapid oxidation of amorphous aluminum by HA and coprecipitation of organic matter with aluminum hydroxide..$^{58,59}$ The removal was about $46 \%$ in presence of 5 ppm HA which was decreased to $34 \%$ when HA concentration was 20 ppm.

3.2.6 Effect of bicarbonate ions. In the environmentally relevant conditions, carbonate speciation suggests bicarbonate ions as the dominant specie and these ions are very commonly present in natural environment with the concentrations ranging from 0.5 to $8 \mathrm{mM}$ in aqueous environment. Hence, it is essential to study the change in removal efficiency of adsorbent in the presence of varying bicarbonate concentrations. These bicarbonate ions can be adsorbed on mineral oxide surfaces strongly over a wide $\mathrm{pH}$ range. $\mathrm{HCO}_{3}{ }^{-}$can reduce the sorption of anionic species due to direct competition for binding sites on sorbent. ${ }^{60,61}$ Little complex mechanism can occur in case of positively charged species (i.e. heavy metal ions) which involves soluble carbonate complexes and formation of precipitates as

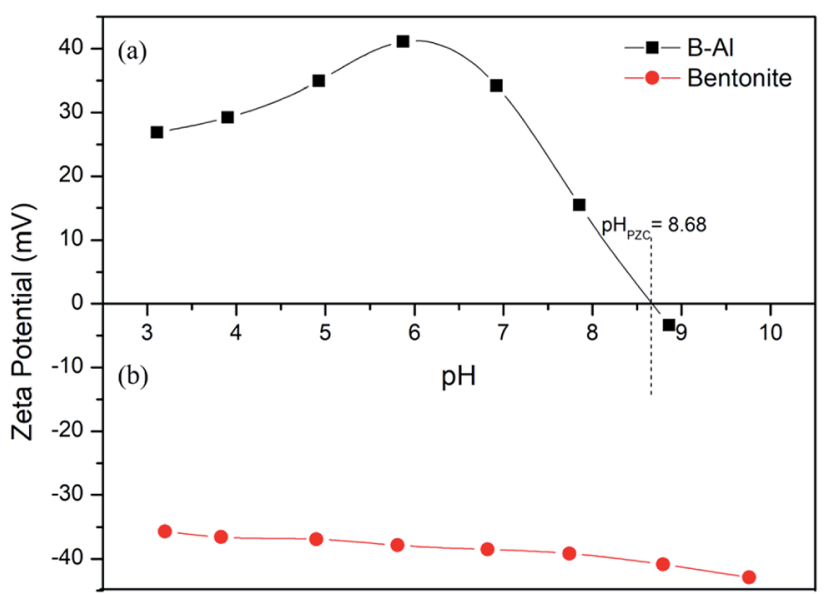

Fig. 9 Zeta potential as a function of $\mathrm{pH}$ and point of zero charge $\left(\mathrm{pH}_{\mathrm{PZC}}\right)$ for (a) B-Al nanocomposite and (b) bentonite. 


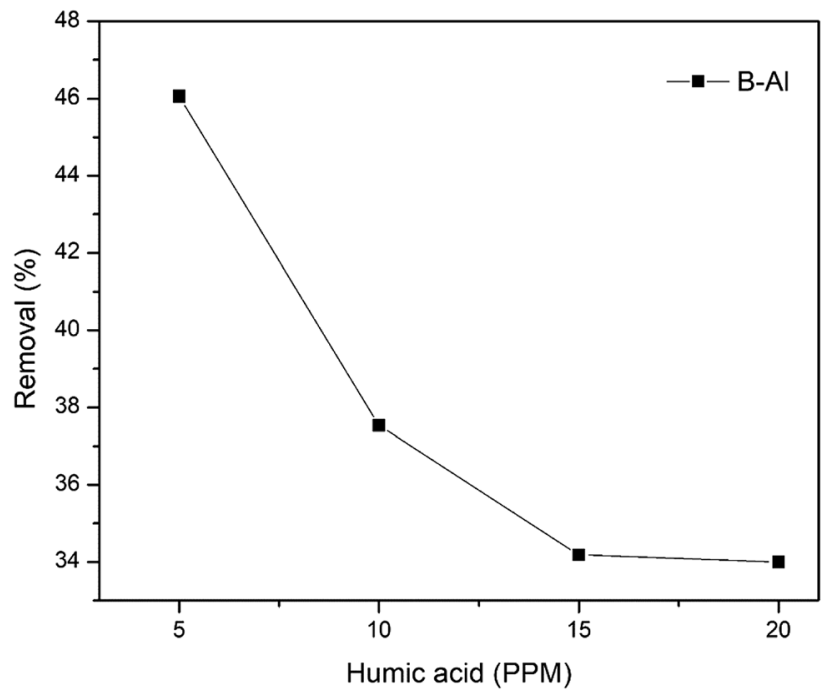

Fig. 10 Effect of humic acid on sorption of $\mathrm{Cr}(\mathrm{VI})$ on $\mathrm{B}-\mathrm{Al}$ nanocomposite.

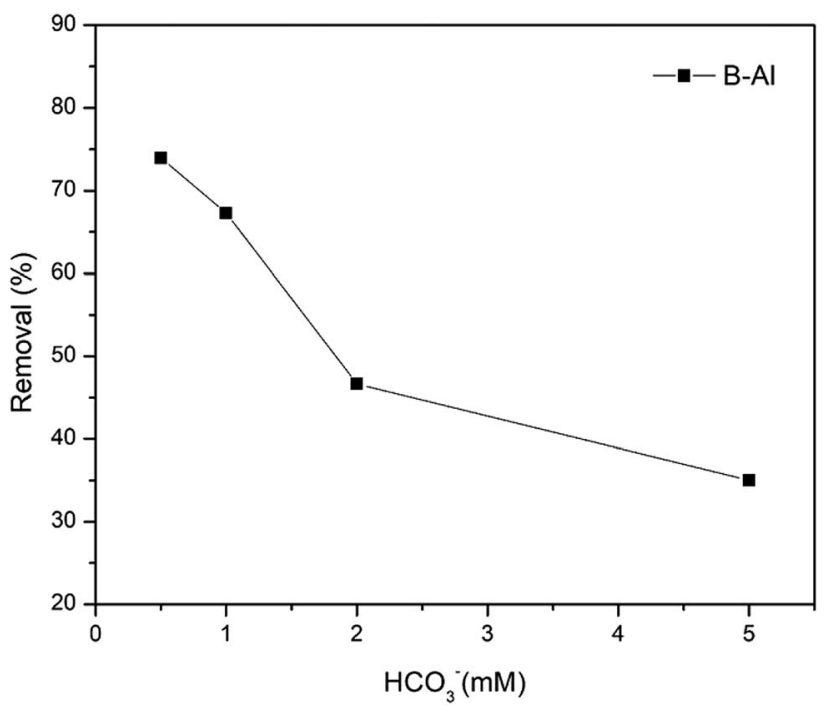

Fig. 11 Effect of bicarbonate ion $\left(\mathrm{HCO}_{3}{ }^{-}\right)$concentration on removal of $\mathrm{Cr}(\mathrm{vI})$.

well. Varying concentrations of $\mathrm{HCO}_{3}{ }^{-}(0.5 \mathrm{mM}$ to $5 \mathrm{mM})$ were spiked and change in removal\% was observed (Fig. 11). Data shows a drastic decrease in $\mathrm{Cr}(\mathrm{vI})$ sorption capacity of adsorbent. This may be due to rapid adsorption of $\mathrm{HCO}_{3}{ }^{-}$ions on surface of bentonite-amorphous aluminum nanocomposite which inhibits the sorption of present anionic $\mathrm{Cr}(\mathrm{vI})$ species. $^{62}$

\section{Conclusions}

A novel nanocomposite i.e. amorphous aluminum modified bentonite (B-Al nanocomposite) was successfully synthesized using $\mathrm{NaBH}_{4}$ reduction method and was utilized for the removal of $\mathrm{Cr}(\mathrm{vI})$ from aqueous solutions. Synthesized $\mathrm{B}-\mathrm{Al}$ nanocomposite shows excellent sorption capacity for $\mathrm{Cr}(\mathrm{vI})$ with a maximum of $49.5 \mathrm{mg} \mathrm{g}^{-1}$. Simultaneous adsorption, rapid reduction, alum formation and precipitation resulted in very rapid removal of $\mathrm{Cr}(\mathrm{vI})$ as $>90 \%$ of chromium was removed from the solution within 5 minutes of interaction. Chemisorption is the major removal mechanism as revealed by well fit of pseudo $2^{\text {nd }}$ order kinetic model and Langmuir, Freundlich, Temkin isotherm models. No effect of increased ionic strength was due to formation of strong inner sphere complexes. Presence of higher concentrations of humic acid and bicarbonate ions reduced the sorption capacity significantly. There was no such effect of solution $\mathrm{pH}$ and temperature on sorption which suggests its suitability in various environmental conditions. Alum precipitation and sorption of secondary contaminants (if any) by bentonite clay make it an ecofriendly nanosorbent for toxic metal ions.

\section{Conflicts of interest}

There are no conflicts to declare.

\section{Acknowledgements}

We gratefully acknowledge the financial support from Ramanujan Fellowship grant from (SB/S2/RJN-006/2016) and ECR project (ECR/2017/000707) from DST, India. We are thankful to Indian Institute of Science Education and Research Kolkata's central instrumentation facility for sample analysis (SEM, TEM, XRD, FTIR and UV-Vis).

\section{References}

$1 \mathrm{X}$. Y. Wu, et al., A review of toxicity and mechanisms of individual and mixtures of heavy metals in the environment, Environ. Sci. Pollut. Res., 2016, 23(9), 82448259.

2 L. Jarup, Hazards of heavy metal contamination, Br. Med. Bull., 2003, 68, 167-182.

3 G. K. Darbha, A. Ray and P. C. Ray, Gold nanoparticle-based miniaturized nanomaterial surface energy transfer probe for rapid and ultrasensitive detection of mercury in soil, water, and fish, ACS Nano, 2007, 1(3), 208-214.

4 G. K. Darbha, et al., Selective detection of mercury (II) ion using nonlinear optical properties of gold nanoparticles, $J$. Am. Chem. Soc., 2008, 130(25), 8038-8043.

5 R. Saha, R. Nandi and B. Saha, Sources and toxicity of hexavalent chromium, J. Coord. Chem., 2011, 64(10), 17821806.

6 J. Guertin, et al., Chromium (VI) handbook, Boca Raton, Fla, CRC Press, 2005, p. 784.

7 World Health Organization, Guidelines for drinking-water quality, World Health Organization, Geneva, 4th edn, 2011, xxiii, p. 541.

8 Agency, U.S.E.P., National Primary Drinking Water Regulations, 2012.

9 Standards, B.o.I., Indian Standard drinking water specification, 2012, New Delhi, India. 
10 R. J. Reeder, M. A. A. Schoonen and A. Lanzirotti, Metal Speciation and Its Role in Bioaccessibility and Bioavailability, Rev. Mineral. Geochem., 2006, 64(1), 59-113.

11 A. S. Dharnaik and P. K. Ghosh, Hexavalent chromium [Cr(VI)] removal by the electrochemical ion-exchange process, Environ. Technol., 2014, 35(17-20), 2272-2279.

12 J. A. Korak, R. Huggins and M. Arias-Paic, Regeneration of pilot-scale ion exchange columns for hexavalent chromium removal, Water Res., 2017, 118, 141-151.

13 S. K. Sharma, B. Petrusevski and G. Amy, Chromium removal from water: a review, J. Water Supply: Res. Technol.-AQUA, 2008, 57(8), 541-553.

14 K. Bhowmik, et al., Stable Ni Nanoparticle-Reduced Graphene Oxide Composites for the Reduction of Highly Toxic Aqueous $\mathrm{Cr}(\mathrm{VI})$ at Room Temperature, Langmuir, 2014, 30(11), 3209-3216.

$15 \mathrm{H}$. Jabeen, et al., Enhanced $\mathrm{Cr}(\mathrm{VI})$ removal using iron nanoparticle decorated graphene, Nanoscale, 2011, 3(9), 3583-3585.

16 T. Wang, et al., Synthesis of Core-Shell Magnetic $\mathrm{Fe}_{3} \mathrm{O}_{4} @$ @poly(m-Phenylenediamine) Particles for Chromium Reduction and Adsorption, Environ. Sci. Technol., 2015, 49(9), 5654-5662.

17 R. M. Schneider, et al., Adsorption of chromium ions in activated carbon, Chem. Eng. J., 2007, 132(1-3), 355-362.

18 N. S. Rajurkar, A. N. Gokarn and K. Dimya, Adsorption of Chromium(III), Nickel(II), and Copper(II) from Aqueous Solution by Activated Alumina, Clean: Soil, Air, Water, 2011, 39(8), 767-773.

19 S. Mortazavian, et al., Activated carbon impregnated by zerovalent iron nanoparticles (AC/nZVI) optimized for simultaneous adsorption and reduction of aqueous hexavalent chromium: material characterizations and kinetic studies, Chem. Eng. J., 2018, 353, 781-795.

20 N. N. Fathima, et al., Solid waste removes toxic liquid waste: adsorption of chromium(VI) by iron complexed protein waste, Environ. Sci. Technol., 2005, 39(8), 2804-2810.

21 L. N. Shi, X. Zhang and Z. L. Chen, Removal of chromium (VI) from wastewater using bentonite-supported nanoscale zero-valent iron, Water Res., 2011, 45(2), 886-892.

22 C.-Y. Hu, et al., Hexavalent chromium removal from near natural water by copper-iron bimetallic particles, Water Res., 2010, 44(10), 3101-3108.

23 M. Rivero-Huguet and W. D. Marshall, Influence of various organic molecules on the reduction of hexavalent chromium mediated by zero-valent iron, Chemosphere, 2009, 76(9), 1240-1248.

$24 \mathrm{H}$. Zhou, et al., Influence of complex reagents on removal of chromium(VI) by zero-valent iron, Chemosphere, 2008, 72(6), 870-874.

25 R. Singh, V. Misra and R. P. Singh, Removal of hexavalent chromium from contaminated ground water using zerovalent iron nanoparticles, Environ. Monit. Assess., 2012, 184(6), 3643-3651.

26 T. Liu, D. C. Tsang and I. M. Lo, Chromium(VI) reduction kinetics by zero-valent iron in moderately hard water with humic acid: iron dissolution and humic acid adsorption, Environ. Sci. Technol., 2008, 42(6), 2092-2098.

$27 \mathrm{X}$. Guan, et al., The limitations of applying zero-valent iron technology in contaminants sequestration and the corresponding countermeasures: the development in zerovalent iron technology in the last two decades (1994-2014), Water Res., 2015, 75, 224-248.

$28 \mathrm{Y}$. Li, et al., Hexavalent chromium removal from aqueous solution by adsorption on aluminum magnesium mixed hydroxide, Water Res., 2009, 43(12), 3067-3075.

$29 \mathrm{~S}$. Li, et al., In situ synthesis of layered double hydroxides on gamma- $\mathrm{Al}_{2} \mathrm{O}_{3}$ and its application in chromium(VI) removal, Water Sci. Technol., 2017, 75(5-6), 1466-1473.

$30 \mathrm{~J}$. Adusei-Gyamfi and V. Acha, Carriers for nano zerovalent iron (nZVI): synthesis, application and efficiency, $R S C A d v$., 2016, 6(93), 91025-91044.

31 L. N. Shi, et al., Synthesis, characterization and kinetics of bentonite supported nZVI for the removal of $\mathrm{Cr}(\mathrm{VI})$ from aqueous solution, Chem. Eng. J., 2011, 171(2), 612-617.

32 C. C. Ding, et al., Plasma synthesis of beta-cyclodextrin/ $\mathrm{Al}(\mathrm{OH})_{3}$ composites as adsorbents for removal of $\mathrm{UO}_{2}{ }^{2+}$ from aqueous solutions, J. Mol. Liq., 2015, 207, 224-230.

33 Z. Zhang, et al., Effect of Staphylococcus epidermidis on U(VI) sequestration by Al-goethite, J. Hazard. Mater., 2019, 368, 52-62.

34 J. Shao, et al., Nanoscale Zero-Valent Iron Decorated on Bentonite/Graphene Oxide for Removal of Copper Ions from Aqueous Solution, Materials, 2018, 11(6), 945.

35 Y. B. Sun, et al., Sequestration of uranium on fabricated aluminum co-precipitated with goethite (Al-FeOOH), Radiochim. Acta, 2014, 102(9), 797-804.

36 B. W. Hu, et al., New insights into Th(IV) speciation on sepiolite: Evidence for EXAFS and modeling investigation, Chem. Eng. J., 2017, 322, 66-72.

37 W. C. Cheng, et al., Fabrication of fungus/attapulgite composites and their removal of $\mathrm{U}(\mathrm{VI})$ from aqueous solution, Chem. Eng. J., 2015, 269, 1-8.

38 Y. B. Sun, J. X. Li and X. K. Wang, The retention of uranium and europium onto sepiolite investigated by macroscopic, spectroscopic and modeling techniques, Geochim. Cosmochim. Acta, 2014, 140, 621-643.

39 R. A. Nyquist, et al., The handbook of infrared and Raman spectra of inorganic compounds and organic salts, Academic Press, San Diego, 1997.

$40 \mathrm{~S}$. Music, et al., Formation of chromia from amorphous chromium hydroxide, Croat. Chem. Acta, 1999, 72(4), 789802.

41 G. A. Ikhtiyarova, et al., Characterization of natural- and organo-bentonite by XRD, SEM, FT-IR and thermal analysis techniques and its adsorption behaviour in aqueous solutions, Clay Miner., 2012, 47(1), 31-44.

42 Z. X. Chi, et al., Bentonite-supported nanoscale zero-valent iron granulated electrodes for industrial wastewater remediation, $R S C A d v .$, 2017, 7(70), 44605-44613.

43 H. H. Teng, et al., Removal of Hexavalent Chromium from Aqueous Solutions by Sodium Dodecyl Sulfate Stabilized Nano Zero-Valent Iron: A Kinetics, Equilibrium, 
Thermodynamics Study, Sep. Sci. Technol., 2013, 48(11), 1729-1737.

44 Y. S. Ho and G. McKay, Pseudo-second order model for sorption processes, Process Biochem., 1999, 34(5), 451-465.

45 Y. S. Ho, Review of second-order models for adsorption systems, J. Hazard. Mater., 2006, 136(3), 681-689.

46 J.-P. Simonin and J. Bouté, Intraparticle diffusionadsorption model to describe liquid/solid adsorption kinetics, Rev. Mex. Ing. Quim., 2016, 15(1), 161-173.

47 H. K. Boparai, M. Joseph and D. M. O'Carroll, Kinetics and thermodynamics of cadmium ion removal by adsorption onto nano zerovalent iron particles, J. Hazard. Mater., 2011, 186(1), 458-465.

48 B. Choudhary and D. Paul, Isotherms, kinetics and thermodynamics of hexavalent chromium removal using biochar, J. Environ. Chem. Eng., 2018, 6(2), 2335-2343.

$49 \mathrm{~S}$. Goldberg, Inconsistency in the triple layer model description of ionic strength dependent boron adsorption, J. Colloid Interface Sci., 2005, 285(2), 509-517.

$50 \mathrm{Y}$. Zhang, et al., Effects of ionic strength on removal of toxic pollutants from aqueous media with multifarious adsorbents: A review, Sci. Total Environ., 2019, 646, 265-279.

51 M. C. S. Faria, et al., Arsenic removal from contaminated water by ultrafine delta-FeOOH adsorbents, Chem. Eng. J., 2014, 237, 47-54.

52 W. Stumm, The Inner-Sphere Surface Complex, in Aquatic Chemistry, American Chemical Society, 1995. pp. 1-32.

53 H. T. Ren, et al., Effects of pH and Anion Species on $\mathrm{Cr}(\mathrm{VI})$ Removal by Magnetite, Fundamental of Chemical Engineering, 2011, 233-235, 1055-1058.
54 P.-I. Au and Y.-K. Leong, Rheological and zeta potential behaviour of kaolin and bentonite composite slurries, Colloids Surf., A, 2013, 436, 530-541.

55 P. Wang, et al., Halloysite nanotube@carbon with rich carboxyl groups as a multifunctional adsorbent for the efficient removal of cationic $\mathrm{Pb}(\mathrm{ii})$, anionic $\mathrm{Cr}(\mathrm{vi})$ and methylene blue (MB), Environ. Sci.: Nano, 2018, 5(10), 2257-2268.

56 G. R. Aiken, Humic substances in soil, sediment, and water: geochemistry, isolation, and characterization, Wiley, New York, 1985, xiii, p.692.

57 S. J. Boggs, D. Livermore, and M. G. Seitz, Humic substances in natural waters and their complexation with trace metals and radionuclides: a review, [129 references], 1985, Argonne National Lab, IL (USA), p. medium: ED; size: p. 118.

58 M. R. Jekel, Interactions of humic acids and aluminum salts in the flocculation process, Water Res., 1986, 20(12), 15351542.

59 E. Tipping, et al., $\mathrm{Al}(\mathrm{III})$ and $\mathrm{Fe}(\mathrm{III})$ binding by humic substances in freshwaters, and implications for trace metal speciation, Geochim. Cosmochim. Acta, 2002, 66(18), 32113224.

60 I. M. C. Lo, C. S. C. Lam and K. C. K. Lai, Hardness and carbonate effects on the reactivity of zero-valent iron for Cr(VI) removal, Water Res., 2006, 40(3), 595-605.

61 J. M. Zachara, et al., Chromate Adsorption on Amorphous Iron Oxyhydroxide in the Presence of Major Groundwater Ions, Environ. Sci. Technol., 1987, 21(6), 589-594.

62 M. Villalobos, M. A. Trotz and J. O. Leckie, Surface complexation modeling of carbonate effects on the adsorption of $\mathrm{Cr}(\mathrm{VI}), \mathrm{Pb}(\mathrm{II})$, and $\mathrm{U}(\mathrm{VI})$ on goethite, Environ. Sci. Technol., 2001, 35(19), 3849-3856. 